\title{
Development of the UTAUT2 model to measure the acceptance of medical laboratory portals by patients in Shiraz
}

\author{
Ramin Ravangard ${ }^{1}$, Zhila Kazemi ${ }^{2}$, Somaye Zaker Abbasali ${ }^{3}$, Roxana Sharifian ${ }^{4}$, Hossein Monem ${ }^{5}$
}

${ }^{1}$ Assistant Professor in Healthcare Services Management, Health Human Resource Research Center, School of Management and Medical Information Sciences, Shiraz University of Medical Sciences, Shiraz, Iran

${ }^{2}$ M.Sc. in Medical Informatics, Student Research Committee, School of Management and Medical Information Sciences, Shiraz University of Medical Sciences, Shiraz, Iran

3 Ph.D. Student of Medical Informatics, Department of Management and Medical Information Sciences, Paramedical school, Tehran University of Medical Sciences, Tehran, Iran

${ }^{4}$ Associate Professor in Health Information Management, School of Management and Medical Information Sciences, Shiraz University of Medical Sciences, Shiraz, Iran

${ }^{5}$ Assistant Professor in Information Systems, Faculty of Paramedicine, Shiraz University of Medical Sciences, Shiraz, Iran

\section{Type of article: Original}

\begin{abstract}
Introduction: One of the main stages for achieving the success is acceptance of technology by its users. Hence, identifying the effective factors in successful acceptance of information technology is necessary and vital. One such factor is usability. This study aimed to investigate the software usability in the "Unified Theory of Acceptance and Use of Technology 2 (UTAUT2)" model in patients' use of medical diagnosis laboratories' electronic portals in 2015.

Methods: This cross-sectional study was carried out on 170 patients in 2015. A 27-item questionnaire adopted from previous research and the Usability Evaluation questionnaire were used for data collection. Data were analyzed using Structural Equation Modeling (SEM), with Partial Least Squares approach by SPSS 20.0 and Smart-PLS V3.0.

Results: The results showed that the construct of intention to use had significant associations with price value ( $\mathrm{t}$ value $=2.77)$, hedonic motivation $(\mathrm{t}-\mathrm{value}=4.46)$, habit $(\mathrm{t}$-value $=1.99)$ and usability $(\mathrm{t}$-value $=5.2)$, as well as the construct of usage behavior with usability ( $\mathrm{t}$-value $=3.45)$ and intention to use $(\mathrm{t}-\mathrm{value}=2.03)$.

Conclusion: Considering the results of this study, the following recommendations can be made in order for the higher use of portals by the patients: informing patients about the advantages of using these portals, designing portals in a simple and understandable form, increasing the portals' attractiveness, etc.

Keywords: Laboratory portal, UTAUT2, Usability, Information technology acceptance
\end{abstract}

\section{Introduction}

Health care providers have long wished to access patients' information for more effective diagnosis and treatment. The rapid growth of information and communication technology (ICT) has a tremendous impact on life, communications and businesses, so that it has led individuals, organizations and governments intentionally or unintentionally, to the optimal use of existing information technology (1-3). However, although the improvement of information technology in the health care sector has been impressive, due to the nature of health organizations and other economic features and expectations of patients, compared with customers of other businesses, the development and the use of information technology has been insufficient (4). The Use of ICT in providing health services as an Ehealth issue is very broad, and includes various activities related to the use of Internet technology and ecommerce

\section{Corresponding author:}

Assistant Professor Dr. Hossein Monem, Faculty of Paramedicine, Shiraz University of Medical Sciences, Shiraz, Iran. Tel.: +989177112168, Email: ali.monem@gmail.com

Received: March 01, 2016, Accepted: October 18, 2016, Published: February 2017

iThenticate screening: August 03, 2016, English editing: December 14, 2016, Quality control: January 20, 2017

(C) 2017 The Authors. This is an open access article under the terms of the Creative Commons Attribution-NonCommercialNoDerivs License, which permits use and distribution in any medium, provided the original work is properly cited, the use is non-commercial and no modifications or adaptations are made. 
infrastructure for the purpose of facilitating the delivery of health services (5). The Internet has many advantages, including interaction and easy access to information and resources, which improves the quality of the service and speeds up the treatment. That makes it a new source of free dissemination of health information and a step further towards an information revolution. Over time, the use of the Internet as a primary source of health advice and information, has increased (2, 6-9). In order to facilitate access to online sources, some health care organizations have created patient portals (10). According to Osborne and colleagues, the secure Internet-based operating system called patients portals means that patients are able to see their personal health information, as well as some portals which allow two-way communication between the patients and the health care providers through messages, and patients are now able to schedule medical appointments and complete re-applications for the drugs (11). In the first practical steps to benefit from these advantages, IT users are required to initially accept the use of technology (12). However, issues related to the acceptance have become so important, coextensive with the increasing influence of the use of information technology in the health care sector (13). Implemented IT projects in the health sector have shown that acceptance in the final users is a major cause of the success of software projects (14). Therefore, understanding the factors that influence the acceptance of information technology will not only be effective, in the design of information systems but also be more efficient in the evaluation, the procedures and the implementation of this technology $(14,15)$. Thus, studying the acceptance of information technology in organizations, can reveal the hidden and affecting factors in better acceptance of technology and reduce the costs. Although several studies have evaluated the behavior and attitude of the users towards the use of new technology from different perspectives, in developing countries there are the lack of studies and efficient tools to evaluate the acceptance of the technology by patients (16-19). Another limitation of previous studies was the selection of doctors and health care organizations as a target group, that practically important factors such as cost, usage and the ability to use technology from the perspective of the patients, were not considered (16-19). To evaluate the different factors that determine individual people's intention to accept the new technology, different models based on the target groups' social psychology have been studied in different institutional environments by the researchers (20-23). However, the most notable model has been introduced as 'Unified Theory of Acceptance and Use of Technology (UTAUT)', by Venkatesh and colleagues in 2003. This model was extracted from the eight previous theoretical models that includes theory of reasoned action (TRA), Social Cognitive Theory (SCT), technology acceptance model (TAM), theory of planned behavior (TPB), motivational model, model of PC utilization (MPCU, Combined TAM and TPB (C-TAM-TPB) and innovation diffusion theory (IDT. $(3,20)$ The UTAUT model is used to voluntarily determine the acceptance and use of technology. This model was completed and developed in 2012 by Prof. Venkatesh and colleagues as Unified Theory of Acceptance and Use of Technology. The aim of their study was implication of the 'Unified Theory of Acceptance and Use of Technology in other areas based on the users, with identifying the three key structures, and changing some relations of the original concepts of UTAUT and introducing the new relationships and the Unified Theory of Acceptance and Use of Technology (24). Firstly, in the IT research and users' behavior, the importance of the various structures related to hedonic motivations in the products and services and using technology was discovered (25-27). Second, in the field of providing technology to the consumer (individual) contrary to work in an organization, users have to pay for using technology that affects the decision making in technology acceptance individually $(25,27,28)$. Third, the accession of habit is considered as UTAUT primary factor driving behavior (2931 ) and has direct effect on the acceptance or use of the technology. Therefore, in addition to the four common variables (expected performance, Effort Expectancy, Social Influence and facilitating conditions) with UTAUT, three key variables of hedonic motivation, price value and habit, as independent variables, were added to UTAUT model (24). By reviewing the literature related to the theories and effective models of technology acceptance, focusing on UTAUT and UTAUT2 models, this result can be deduced that Venkatesh only examined and investigated the Unified Theory of Acceptance and Use of Technology from the psychological point of view while, in other models such as "the measure of success of information systems", another factor named usability to use the information technology has been pointed out (32). The Measures of Success Information Systems 2013 model, was introduced by Monem and her colleagues, based on DeLone and McLean (1992-2003), to study and development of measuring the success rate of information systems in 2013. Moreover, after evaluating the previous success models, they found that the user's role in the success of an information system had been overlooked when the system is mandatory. User's roles include user participation, user involvement and user engagement, which are influential in the success of information systems. "User participation" is defined as observable behavior of users in the process of developing an information system. "User's involvement" is considered as public attitude or state of mind of the user and "user engagement" is a set of behaviors and attitudes towards the information systems. On the other hand, in some studies it has proven that problems of usability are one of the most important negative factors affecting the acceptance $(33,34)$ and effectiveness of the (35-37) applications. The usability is one of the features of the product that affects the quality of software, and has been recognized as a most important aspect of software quality (38). The 
usability can be defined in a wide range as the capacity of a system that allows users to perform their duties safely, effectively, efficiently and enjoyably $(39,40)$. According to the ISO 9126 , usability is "the ability of a software product in respect of understanding to learn and use, and is engaging for users when it is applied in a concrete situation" (41). This model is recognized as standard for quality evaluation features and instructions for using the software. This kind of quality model, first released in 1991, has been modified over ten years by ISO software engineers. This international standard defined the quality of software in six broad categories of functionality features, reliability, usability, maintainability, portability and efficacy, and is classified in four understandable dimensions of understandability, learnability and attractiveness. Therefore, in the proposed model, hedonic motivation, price value and habit of the UTAUT2, usability and ability, the technology of the Monem and colleagues' model and the applicability of the ISO 9126 model were used. The aim of this study is to develop "THE UNIFIED THEORY OF ACCEPTANCE AND USE OF TECHNOLOGY 2" (UTAUT2) and the use of measuring tools and measurement factors in clinical laboratories in accepting electronic portals. In preliminary study it was found that among 188 clinical laboratories in Fars province, just 20 of them have a website to deliver electronic services while none of the patients use of predicted services. This is the main promoter to encourage authors to conduct this research on the measure of acceptance of the medical laboratory website in Shiraz, Fars, Iran. Finally, this paper reviews the literature related to measurement models to introduce the researcher's considered conceptual model and then, the research method and the results are presented and discussed.

\section{Material and Methods}

\subsection{Research design and sampling}

This was a cross-sectional study that was conducted in August 2015. A sample of patients who had come to public (Faghihi and Ali Asghar) and private (Daneshbod and Laboratory of Oil Company) laboratories in Shiraz (Iran) were interviewed via the questionnaire. At least one previous use of electronical services of these laboratories was considered as inclusion criteria. The sample size was determined as 126 patients based on the findings of the pilot study, and assuming the $1-\beta=80 \%, \alpha=0.05$ and $r=0.224$, by considering the risk of non-compliance in completing the questionnaire or incomplete questionnaires, 170 patients were selected, and questionnaires were distributed among them. For sampling, stratified sampling method proportional to size was used to determine the number of cases in each center and also convenience sampling method, to select the patients using portals and the questionnaires in each center.

\subsection{Questionnaires, validity and reliability}

The questionnaire of our study consisted of two parts: demographic and the model's constructs questions. Demographic questions included age, sex, education, etc. The constructs questions of the model were habit, hedonic motivation, price value, ability to use information technology, usability, behavioral intention and use, and each construct was evaluated via indices or questions, as presented in the table. Five choices for each point of the Likert scale for scoring of the questions were as follows. Strongly agree $=5$, agree $=4$, mean $=3$, disagree $=2$, strongly disagree $=1$. After designing the questionnaire and confirming its validity by a panel of experts, a total of 30 patients using laboratory portals in Shiraz were selected randomly, while the reliability of the questionnaire was measured and evaluated by Cronbach's alpha $\alpha$ in IBM@ SPSS $\odot$ Statistics version 20 (IBM@ Corp., Armonk, NY, USA).

\subsection{Data collection and statistical analysis}

Data was gathered from 170 patients who at least one time, used the electronic lab services in public and private laboratories in Shiraz city in August 2015. The patients were selected randomly, and after the oral consent of patients, they were interviewed with the questionnaire. In this study, the structural equation modeling approach and partial least squares fit of the model was used to test the hypothesis. PLS approach is based on the variance compared to the same techniques, as confirmatory, Amos structural equation requires fewer conditions (42). For example, in contrast to LISREL, PLS path modeling is more suitable for real applications. Particularly when models are more complex or the distribution of data is not-normal, the use of this approach would be more appropriate (43). The main advantage of PLS modeling compared to LISREL is that a smaller number of samples are required (44). In the PLS method, validity of the model in three dimensions of evaluation of measurement model, evaluation of the structural model and the overall evaluation of the model will be conducted. For the measurement of reliability indices (Cronbach's alpha, combined reliability), convergent validity (mean-variance approach developed (AVE)) and validity divergent (Fornell and Larcker) were used. For the structural model, coefficient t-values and R2 were used. In the overall assessment, measure of GOF test model was used. Cronbach's alpha and composite reliability according to numbers reported in Table 1, all structures that are the structural model of this research have good reliability. Two criteria of Cronbach's alpha and composite reliability were used for the reliability of the structures. 
Optimal for the high Cronbach's alpha is 0.7 and 0.8 for composite reliability, and up to the 0.7 is acceptable ( 45 , 46). Validity is measured in two ways using convergent and divergent methods. In the convergent validity of the scale, the AVE is used to its optimum level higher than 5.0 for each listed variable. Regarding divergent validity as a complementary concept and Fornell- Larcker and testing criteria outlined transverse loads are its two criteria. Fornell-Larcker claim that divergent validity is at an acceptable level when the AVE for each structure is more than the shared variance between that structure and other structures (squared correlation coefficient between the structures) (45). After measuring the validity and reliability of the model, the determined structural model was evaluated by the relationship between latent variables. Therefore, the path and the amount of variance explained (R2) endogenous variables (dependent) were studied. The greater amount of the R2 value for endogenous structural model is indicative of a better fitting model. China (1998), introduced the three amounts of 0.19, 0.33, 0.67 as the basis for the values flow, medium, and strong R2 (47). So, weak, medium and strong and fitness of the structural model is determined by R2 standard. Overall, the model includes both the measurement model and structural model which, by its approval evaluation of the model is complete. In PLS software, fitness of the model is obtained from the Houston and colleagues model formula. The value model must be greater than 0.36 . So that GOF is indicative of the mean shared amount of any structure, as well as the average values of R Squares structures endogenous model (45).

\subsection{Research ethics}

The ethic committee of Shiraz University of Medical Sciences approved the research proposal. Also, we provided all necessary information to participants and their oral consent was obtained.

Table 1. Composite reliability of all values of independent and dependent variables.

\begin{tabular}{|l|l|l|}
\hline Structures & CPR & Cronbach's alpha \\
\hline Price value & 0.846 & 0.764 \\
\hline Habit & 0.865 & 0.790 \\
\hline Hedonic motivation & 0.865 & 0.809 \\
\hline Usability & 0.900 & 0.867 \\
\hline The ability to use technology & 0.886 & 0.921 \\
\hline Behavioral intention & 0.924 & 0.891 \\
\hline Use Behavior & 1 & 1 \\
\hline
\end{tabular}

\section{Results}

Cronbach's alpha in this study was calculated and high value of 0.911 was obtained for all alpha values for all questions, so none of the questions were removed. Based on the results, 113 of the users $(66.5 \%)$ were women, 57 users (33.5\%) were males, most age groups belonging to the age group under 30 years. Regarding Cronbach's alpha, all the structures of the structural models of this research have desirable reliability. Also, Table 2 shows that all variables have had a good convergent and divergent validity. After the measurement of the validity and reliability of the model, the determined structural model was evaluated by the relationship between the latent (invisible) variables. The value of calculated R2 in this study, for the variable "behavioral intention", was 0.592 and for the " use behavior ", was 0.072 which indicates that in this study, we could measure the "behavioral intention with power of, 0.592 and" behavior use "of 0.072 . Also, good of fitness (GOF) was 0.472 , which is approved as the desirable fitting of the overall model. According to the results, hypotheses were tested and the results are presented in Table 3 .

Table 2. Results of Fornell - Larcker (Fornell - Larcker Criterion) developed and mean-variance (AVE) indices

\begin{tabular}{|l|l|l|l|l|l|l|l|l|}
\hline & AVE & $\begin{array}{l}\text { Price } \\
\text { value }\end{array}$ & Habit & $\begin{array}{l}\text { Hedonic } \\
\text { motivation }\end{array}$ & Usability & $\begin{array}{l}\text { The ability to use } \\
\text { technology }\end{array}$ & $\begin{array}{l}\text { Behavioral } \\
\text { intention }\end{array}$ & Use \\
\hline Price value & 0.680 & $\mathbf{0 . 8 2 4}$ & & & & & & \\
\hline Habit & 0.619 & 0.561 & $\mathbf{0 . 7 8 6}$ & & & & & \\
\hline $\begin{array}{l}\text { Hedonic } \\
\text { motivation }\end{array}$ & 0.567 & 0.527 & 0.540 & $\mathbf{0 . 7 5 2}$ & & & & \\
\hline Usability & 0.601 & 0.327 & 0.405 & 0.546 & $\mathbf{0 . 6 5 8}$ & & & \\
\hline $\begin{array}{l}\text { The ability to } \\
\text { use technology }\end{array}$ & 0.725 & -0.026 & - & 0.099 & 0.112 & 0.724 & & \\
\hline $\begin{array}{l}\text { Behavioral } \\
\text { intention }\end{array}$ & 0.757 & 0.531 & 0.538 & 0.673 & 0.619 & 0.124 & $\mathbf{0 . 8 8 0}$ & \\
\hline Use Behavior & 1 & 0.042 & 0.142 & 0.121 & 0.230 & 0.068 & 0.619 & $\mathbf{1}$ \\
\hline
\end{tabular}


Table 3. Result of examining the hypotheses

\begin{tabular}{|l|l|l|l|l|}
\hline \multicolumn{2}{|l|}{ Hypothesis } & $\begin{array}{l}\text { Path } \\
\text { coefficient }\end{array}$ & $\begin{array}{l}\text { t- } \\
\text { value }\end{array}$ & Result \\
\hline H1 & $\begin{array}{l}\text { Between the score of "hedonic motivation" with the score of "Behavioral } \\
\text { intention" patients in the use of electronic portals and private clinical } \\
\text { laboratories in Shiraz }\end{array}$ & 0.180 & 4.46 & $\begin{array}{l}\text { Not } \\
\text { rejected }\end{array}$ \\
\hline H2 & $\begin{array}{l}\text { Between the score of "price value" by the score of "Behavioral intention" } \\
\text { patients in the use of electronic portals and private clinical laboratories in } \\
\text { Shiraz }\end{array}$ & 0.320 & 2.77 & $\begin{array}{l}\text { Not } \\
\text { rejected }\end{array}$ \\
\hline H3 & $\begin{array}{l}\text { Between the score of "habit" with a score of "Behavioral intention" patients } \\
\text { in the use of electronic portals and private clinical laboratories in Shiraz. }\end{array}$ & 0.139 & .1 .99 & $\begin{array}{l}\text { Not } \\
\text { rejected }\end{array}$ \\
\hline H4 & $\begin{array}{l}\text { Between the score of "habit" with a score of "Use Behavior" in public and } \\
\text { private clinical laboratories using electronic patient portals. }\end{array}$ & 0.118 & 1.59 & Rejected \\
\hline H5 & $\begin{array}{l}\text { Between the score of "The ability to use the technology" with a score of } \\
\text { "Behavioral intention" patients in the use of electronic portals and private } \\
\text { clinical laboratories in Shiraz. }\end{array}$ & 0.072 & 1.73 & Rejected \\
\hline H6 & $\begin{array}{l}\text { Between the score of "The ability to use the technology" with a score of } \\
\text { "Use Behavior" in public and private clinical laboratories using electronic } \\
\text { patient portals. }\end{array}$ & -0.006 & 0.14 & Rejected \\
\hline H7 & $\begin{array}{l}\text { Between the score of "user experience" with a score of "" Behavioral } \\
\text { intention" patients in the use of electronic portals and private clinical } \\
\text { laboratories in Shiraz. }\end{array}$ & 0.321 & 5.52 & $\begin{array}{l}\text { Not } \\
\text { rejected }\end{array}$ \\
\hline H8 & $\begin{array}{l}\text { Between the score of "user experience" with a score of "Use Behavior" in } \\
\text { public and private clinical laboratories using electronic patient portals. }\end{array}$ & $0.249-$ & 3.45 & $\begin{array}{l}\text { Not } \\
\text { rejected }\end{array}$ \\
\hline H9 & $\begin{array}{l}\text { Between the score of "Behavioral intention" with a score of "Use Behavior" } \\
\text { in public and private clinical laboratories using electronic patient portals. }\end{array}$ & -0.174 & 2.03 & $\begin{array}{l}\text { Not } \\
\text { rejected }\end{array}$ \\
\hline
\end{tabular}

\section{Discussion}

Briefly, the finding of this study that was aimed to develop "Unified Theory of Acceptance and Use of Technology by using two variables "usability" and "user experience" in case of medical laboratories electronic portals use, shows the influence of "hedonic motivation" on the "behavioral intention" which is consistent with studies of Venkatesh (24) and Rodriguez (48). It means that, if consumer's experience of using technology is enjoyable, the use of technology will be repeated $(49,53)$. The second finding is the influence of "price value" on the "behavioral intention", while this one is consistent with the studies of Venkatesh and colleagues (24), and Rodriguez (48) and Yang (50). So, by realizing the benefits of technology more than the cost, it could have a positive impact on the intended use of the technology (24). The cost has an important role as a stimulus for intent to use. This means that more cost savings or the ability to obtain a better product or service in exchange for the cost and benefits perceived by the customer, can have an impact on the intended use of the technology (24). The effect of "habit" was also confirmed on the "intent to treat" by Venkatesh (24), Rodriguez (48), Lewis (51) and Keith (52). Further result is the effect of "usability" on the "behavioral intention". The usability as a set of product's features affects the quality of a software system, and is known as the most important aspect of software quality (38). Thus, applicability in the wide range can be defined as capacity of a system that allows users to perform their duties safely, effectively, efficiently and enjoyably $(39,40)$. According to the findings of the current study, there is a significant relationship between the "usability" and "behavior". According to Jakob Nielsen, usability for web users is very important and if users have problems in using the website; they will leave (53). So, usability is a feature in the portal which can affect the use of the portals. The last outcome of this study is, confirming the relationship between the "behavioral intentions" and the "usage behavior" which is consistent with the findings of the Venkatesh et al. (24), Rodriguez et al. (48), Cheng et al. (54). Lewis et al. (51) and Raman et al. (55), and according to this relationship, we can concluded that intentions to use the technology can lead to the use of it.

\section{Conclusions}

The implementation of new information technology in the health care organizations, for their benefits is growing, while an important requirement for the successful implementation of information technology is its acceptance by their users. So, it is necessary to evaluate the factors affecting users' acceptance. The results of this study show that the structures "price value", "hedonic motivation", "habit" and "usability" have positive and significant impact on 
the "behavioral intention". The structures of "usability" and "behavioral intention" have positive and significant impact on the "Use Behavior". Therefore, managers and administrators should enhance the intention of using lab portals in patients that leads to making "price value", "hedonic motivation", "habit" and "usability or user experience" in the portal. Based on the findings of this study, it is suggested that patients and users should be aware of the advantages of the portals through advertising, because it increases the patient's perception of the benefits of receiving services through the portal, and reduces their tendency to get the results of their lab testing personally, and this creates added value for them. For hedonic motivation and usability, portals should be designed attractively with regard to color, font, and in addition, with the documentation related to easy learning, the use of portals for patients and consumers should be available.

\section{Acknowledgments:}

The present article was extracted from the thesis written by Zhila Kazemi and was financially supported by Shiraz University of Medical Sciences (grants No. 94-7444). The authors would like to thank all the people who helped them to conduct this research.

\section{Conflict of Interest:}

There is no conflict of interest to be declared.

\section{Authors' contributions:}

All authors contributed to this project and article equally. All authors read and approved the final manuscript.

\section{References:}

1) Ami-Narh JT, Williams PA. A revised UTAUT Model to Investigate E-health Acceptance of Health Professionals in Africa. Journal of Emerging Trends in Computing and Information Sciences. 2012; 3(10).

2) González ME, Quesada G, Urrutia I, Gavidia JV. Conceptual Design of an E-health Strategy for the Spanish Health Care System. Int J Health Care Qual Assur Inc Leadersh Health Serv. 2006; 19(2): 146-57. doi: 10.1108/09526860610651681. PMID: 16875096.

3) Taiwo AA, Downe AG. The Theory of User Acceptance and Use of Technology (UTAUT): A MeatAnalytic Review of Empirical Findings. Journal of Theoretical and Applied Information Technology. 2013; 49(1): 48-58.

4) Dünnebeil S, Sunyaev A, Blohm I, Leimeister JM, Krcmar H. Determinants of physicians' technology acceptance for e-health in ambulatory care. Int $\mathrm{J}$ Med Inform. 2012; 81(11): 746-60. doi: 10.1016/j.ijmedinf.2012.02.002. PMID: 22397989.

5) Wickramasinghe NS, Fadlalla AM, Geisler E, Schaffer JL. A Framework for Assessing E-health Preparedness. Int J Electron Healthc. 2005; 1(3): 316-34. doi: 10.1504/IJEH.2005.006478. PMID: 18048213.

6) Jadad AR, Gagliardi A. Rating Health Information on the Internet: Navigating to Knowledge or to Babel? JAMA. 1998; 279(8): 611-4. doi: 10.1001/jama.279.8.611. PMID: 9486757.

7) Chang MY, Han DH, Moon IJ, Kim ST, Kim DY, Lee CH, et al. Assessment of Allergic Rhinitis Websites in Korea. Clin Exp Otorhinolaryngol. 2010; 3(1): 32-6. doi: 10.3342/ceo.2010.3.1.32. PMID: 20379400, PMCID: PMC2848316.

8) Silberg WM, Lundberg GD, Musacchio RA. Assessing, controlling, and assuring the quality of medical information on the Internet: Caveant lector et viewor--Let the reader and viewer beware. JAMA. 1997; 277(15): 1244-5. doi: 10.1001/jama.1997.03540390074039. PMID: 9103351.

9) Berland GK, Elliott MN, Morales LS, Algazy JI, Kravitz RL, Broder MS, et al. Health Information on the Internet: Accessibility, Quality, and Readability in English and Spanish. JAMA. 2001; 285(20): 2612-21. doi: 10.1001/jama.285.20.2612. PMID: 11368735, PMCID: PMC4182102.

10) Emont S. Measuring the Impact of Patient Portals: What the literature Tells Us. California Healthcare Foundation White Paper; 2011.

11) Osborn CY, Mayberry LS, Wallston KA, Johnson KB, Elasy TA. Understanding Patient Portal Use: Implications for Medication Management. J Med Internet Res. 2013; 15(7): e133. doi: 10.2196/jmir.2589. PMID: 23823974, PMCID: PMC3713921.

12) Europe ECR, Berger R. Efficient replenishment and EDI: ECR Europe; 1996.

13) Schaper LK, Pervan GP. ICT and OTs: A Model of Information and Communication Technology Acceptance and Utilisation by Occupational Therapists. Int J Med Inform. 2007; 76: S212-21. doi: 10.1016/j.ijmedinf.2006.05.028. PMID: 16828335. 
14) Kijsanayotin B, Pannarunothai S, Speedie SM. Factors influencing health information technology adoption in Thailand's community health centers: Applying the UTAUT model. Int J Med Inform. 2009; 78(6): 40416. doi: 10.1016/j.ijmedinf.2008.12.005. PMID: 19196548.

15) Aggelidis VP, Chatzoglou PD. Using a modified technology acceptance model in hospitals. Int J Med Inform. 2009; 78(2): 115-26. doi: 10.1016/j.ijmedinf.2008.06.006. PMID: 18675583.

16) Zheng K, Fear K, Chaffee BW, Zimmerman CR, Karls EM, Gatwood JD, et al. Development and validation of a survey instrument for assessing prescribers' perception of computerized drug-drug interaction alerts. J Am Med Inform Assoc. 2011; 18(Supple 1): i51-61. doi: 10.1136/amiajnl-2010000053. PMID: 21486876, PMCID: PMC3241157.

17) Or CK, Karsh BT. A systematic review of patient acceptance of consumer health information technology. J Am Med Inform Assoc. 2009; 16(4): 550-60. doi: 10.1197/jamia.M2888. PMID: 19390112, PMCID: PMC2705259.

18) Sood SP, Nwabueze SN, Mbarika VWA, Prakash N, Chatterjee S, Ray P, et al. editors. Electronic medical records: a review comparing the challenges in developed and developing countries. Hawaii International Conference on System Sciences. Proceedings of the 41st Annual: IEEE; 2008.

19) Kortemann M, editor. Cultural Background and Technology Acceptance: Evaluation of ICT Projects that Bridge the Digital Divide. IWIPS; 2005.

20) Venkatesh V, Morris MG, Davis GB, Davis FD. User Acceptance of Information Technology: Toward a Unified View. Management Information Systems Quarterly. 2003; 27(3): 425-78.

21) Ajzen I. The Theory of Planned Behavior. Organizational Behavior and Human Decision Processes. 1991; 50(2): 179-211. doi: 10.1016/0749-5978(91)90020-T.

22) Ajzen I, Fishbein M. Belief, Attitude, Intention and Behavior: An Introduction to Theory and Research. Reading, MA: Addison-Wesley; 1975.

23) Davis FD. Perceived Usefulness, Perceived Ease of Use, and User Acceptance of Information Technology. MIS Quarterly. 1989; 13(3): 319-40. doi: 10.2307/249008.

24) Venkatesh V, Thong JY, Xu X. Consumer Acceptance and Use of Information Technology: Extending the Unified Theory of Acceptance and Use of Technology. MIS Quarterly. 2012; 36(1): 157-78.

25) Brown SA, Venkatesh V. Model of Adoption of Technology in Households: A Baseline Model Test and Extension Incorporating Household Life Cycle. MIS Quarterly. 2005; 29(3): 399-426.

26) Van der Heijden H. User Acceptance of Hedonic Information Systems. MIS Quarterly. 2004; 28(4): 695704.

27) Chan KY, Gong M, Xu Y, Thong J. Examining User Acceptance of SMS: an Empirical Study in China and Hong Kong. PACIS 2008 Proceedings. 2008; 9(2): 396-401.

28) Dodds WB, Monroe KB, Grewal D. Effects of Price, Brand, and Store Information on Buyers' Product Evaluations. Journal of Marketing Research. 1991; 28(3): 307-19. doi: 10.2307/3172866.

29) Davis FD, Venkatesh V. Toward Preprototype User Acceptance Testing of New Information Systems: Implications for Software Project Management. IEEE Transactions on Engineering Management. 2004; 51(1): 31-46. doi: 10.1109/TEM.2003.822468.

30) Kim SS, Malhotra NK. A longitudinal Model of Continued IS Use: An Integrative View of Four Mechanisms Underlying Post Adoption Phenomena. Management Science. 2005; 51(5): 741-55. doi: $10.1287 /$ mnsc. 1040.0326 .

31) Kim SS, Malhotra NK, Narasimhan S. Research Note-Two Competing Perspectives on Automatic Use: A Theoretical and Empirical Comparison. Information Systems Research. 2005; 16(4): 418-32. doi: 10.1287/isre. 1050.0070 .

32) Monem H, Afrasiabli M, Rezvan P, Dehkordi SA. The Impact of User Quality and Information Quality on the IS Success in Healthcare Context. Journal of Basic and Applied Scientific Research. 2013; 3(10): 4051.

33) Campbell EM, Guappone KP, Sittig DF, Dykstra RH, Ash JS. Computerized provider order entry adoption: implications for clinical workflow. J Gen Intern Med. 2009; 24(1): 21-6. doi: 10.1007/s11606-008-0857-9. PMID: 19020942, PMCID: PMC2607519.

34) Ash JS, Sittig DF, Dykstra R, Campbell E, Guappone K. The Unintended Consequences of Computerized Provider Order Entry: Findings from a Mixed Methods Exploration. Int J Med Inform. 2009; 78: S69-76. doi: 10.1016/j.ijmedinf.2008.07.015. PMID: 18786852, PMCID: PMC2683676.

35) Ash JS, Berg M, Coiera E. Some Unintended Consequences of Information technology in Health Care: the Nature of Patient Care Information System-related Errors. J Am Med Inform Assoc. 2004; 11(2): 104-12. doi: 10.1197/jamia.M1471. PMID: 14633936, PMCID: PMC353015. 
36) Koppel R, Metlay JP, Cohen A, Abaluck B, Localio AR, Kimmel SE, et al. Role of Computerized Physician Order Entry Systems in Facilitating Medication Errors. JAMA. 2005; 293(10): 1197-203. doi: 10.1001/jama.293.10.1197. PMID: 15755942.

37) Kushniruk AW, Triola MM, Borycki EM, Stein B, Kannry JL. Technology Induced Error and Usability: The Relationship Between Usability Problems and Prescription Errors When Using a Handheld Application. Int J Med Inform. 2005; 74(7): 519-26. doi: 10.1016/j.ijmedinf.2005.01.003. PMID: 16043081.

38) Madan A, Dubey SK. Usability Evaluation Methods: a Literature Review. International Journal of Engineering Science and Technology. 2012; 4(2).

39) Preece J, Rogers Y, Sharp H, Benyon D, Holland S, Carey T. Human-Computer Interaction. AddisonWesley Publishing Company; 1994.

40) Preece J, Rogers Y, Sharp H. interaction design: beyond human-computer interaction. New York: Wiley. 2002.

41) Folmer E, Bosch J. Architecting for usability: a survey. Journal of systems and software. 2004; 70(1): 6178. doi: 10.1016/S0164-1212(02)00159-0.

42) Liljander V, Polsa P, van Riel A. Modelling consumer responses to an apparel store brand: Store image as a risk reducer. Journal of Retailing and Consumer Services. 2009; 16(4): 281-90. doi: 10.1016/j.jretconser.2009.02.005.

43) Wen Wu W. Linking Bayesian Networks and PLS Path Modeling for Causal Analysis. Expert Systems with Applications. 2010; 37(1):134-9. doi: 10.1016/j.eswa.2009.05.021.

44) Wixom BH, Watson HJ. An Empirical Investigation of the Factors Affecting Data Warehousing Success. Management Information Systems Quarterly. 2001; 25(1): 17-32. doi: 10.2307/3250957.

45) Davari A, Rezazadeh A. Structural Equation Modeling With PLS. Tehran: Jahad University. 2013; 215(2): 224.

46) Cronbach LJ. Coefficient Alpha and the Internal Structure of Tests. Psychometrika. 1951; 16(3): $297-334$. doi: 10.1007/BF02310555.

47) Chin WW. The Partial Least Squares Approach to Structural Equation Modeling. Modern Methods for Business Research. 1998; 295(2): 295-336.

48) Escobar Rodríguez T, Carvajal Trujillo E. Online Purchasing Tickets for Low Cost Carriers: An Application of the Unified theory of Acceptance and Use of Technology (UTAUT) Model. Tourism Management. 2014; 43: 70-88. doi: 10.1016/j.tourman.2014.01.017.

49) Ahn T, Ryu S, Han I. The Impact of Web quality and Playfulness on User Acceptance of Online Retailing. Information \& Management. 2007; 44(3): 263-75. doi: 10.1016/j.im.2006.12.008.

50) Yang S. Understanding Undergraduate Students' Adoption of Mobile Learning Model: A Perspective of the Extended UTAUT2. Journal of Convergence Information Technology. 2013; 8(10): 969. doi: 10.4156/jcit.vol8.issue10.118.

51) Lewis CC, Fretwell CE, Ryan J, Parham JB. Faculty Use of Established and Emerging Technologies in Higher Education: A Unified theory of Acceptance and Use of Technology Perspective. International Journal of Higher Education. 2013; 2(2): 22. doi: 10.5430/ijhe.v2n2p22.

52) Coulter KS, Coulter RA. Distortion of price discount perceptions: the right digit effect. Journal of Consumer Research. 2007; 34(2): 162-73. doi: 10.1086/518526.

53) Saeed M, Ullah S. Usability Evaluation of a Health Web Portal: Master Thesis. School of Computing, Blekinge Institute of Technology. Sweden.

54) Chang I, Hwang HG, Hung WF, Li YC. Physicians' Acceptance of Pharmacokinetics-based Clinical Decision Support Systems. Expert Systems with Applications. 2007; 33(2): 296-303. doi: 10.1016/j.eswa.2006.05.001.

55) Raman A, Don Y. Preservice Teachers' Acceptance of Learning Management Software: An Application of the UTAUT2 Model. International Education Studies. 2013; 6(7): 157. doi: 10.5539/ies.v6n7p157. 